These last figures, compared with those of 1902, represent a saving of 46 lives per million, which means that, as there were 18,672,986 women in England in 1911-859 women were saved in 1911 who would have been lost in 1902 .

\section{Infant Morfality.}

Premature Birth, A te!ectasis, Injury at Birth: All due to condi23.6 of all infantilo deaths under one year.

Here again the quality of assistance and attendance given at childbirth will be important determining factors in the rate of iufantile mortality.

SIR,-Dr. Power has addressed you on this question under circumstances which are rather unusual, and are disclosed in the following letter which I have written to Di. Power, and which I shall ask you to publish.-I am, ctc.,

Enniskillen, July 29th.

L. KIIDD.

Dear Dr. Power,

Thank you for your letter. I do not object to criticisms of the Midwives Acts and their application to Ireland, and I am sure the Committee appointed to deal with the matter (which will have further meetings) will be very pleased to consider any suggestions you may put before them.

But, as a member of the Committee and the person who wrote the circular from which you quote, I do object to you, who are not a member of the Committee, publicly criticizing a document which was the property of the Committec flve days before the Committee had met to consider the inatter.

You criticize and quote from a circular, issued only to members of the Committee, to assist them in their deliberations and elicit criticism within the Committee. This circular was not marked private, but, nevertheless, was obviously private and privileged in character ; it was issued individually to members of the Committee on July 17th, your letter was dated July 19th, and the Committee did not meet until July 24th.

Under these circumstances I trust you will forgive me for saying that I consider your action, and that of you "friend" in abusing his privileged position to place a private document at your disposal, equally improper.

I do hope that before you offer any further criticism you will realize that the object of the Midwives Act is not to legalize (as yon appear to think) but to penalize the handy woman, and further that not only will dispensary medical offlcers be "exempted from attending" confinements in conjunction with uncertifled women, but that they will be struck off the IIcdical Register for doing so, except in an cmergency.

Enniskillen, July 29th, 1916

Yours faithfully, L. KIDD.

A CLASSICAL ALLUSION TO ALCOHOLIC DROPSY NO'I' CAUSED BY CIRRHOSIS OF 'THE LIVEP.

SIr,-I liave sometimes wondered what precise kind of general dropsy or "waterlogged" condition Horace referred to by way of simile in the following stanza (Odes, II, ii, 13-16) :

Crescit indulgens sibi divus hydrons, Nec sitim pellit, nisi causa morb Corpore languor.

According to Horace, the "dreadful dropsy" in question is increased by being indulged (that is, by gratifying tho thirst), and the thirst is not got rid of, nor does the dropsical fluid leave the pale swollen body, till the cause of the disease has been removed from the system. Horace had probably seen persons afflicted with dropsy; but what kind of dropsy was this, associated with insatiate thirst? Had he been reading some imaginative medical work on dropsy, or had he acquired peculiar ideas on the subject from conversation with his friends, and from popular theories on the causes of disease current at the time?

I think he must have alluded to some real kind of dropsical condition, one sufficiently known to his friends to make his simile appeal to them. It would have been strange indecd if Horace had tried to illustrate such a well known "vicious circle in psychical life" as that sometimes associated with the hoarding of money and riches (the increase of the vice of avarice which may accompany adrancing years), by comparing it to an almost unknown and possibly imaginary disease of the body.
Yet it must be admitted that dropsy associated with au insatiable desire to drink, like tlie aquosus languor pictured by Horace, is not very frequent nowadays. His description does not correspond to ordinary dropsy of renal, cardiac, or cardio-pulmonary origin, nor to dropsy connected with cirrhosis of the liver. It does, however, to some extent correspond to a form of dropsy which occasionally supervenes in strongly built men who have been accustomed to consume extraordinarily large quantities of relatively weak alcoholic drinks, such as beer, cider, and weals or diluted wines. In some of these cases the patients have had to work in a very liot atmosphere, for instance, at furnaces, or in a baliery, where the sweating (and resulting thirst) is enormous. Such patients are likely to be troubled by the desire to drink, as mentioned by Horace; and moreover, under favourable conditions and with reasonable treatment, they are likely to recover from their dropsy. I do not mean to say that they have no disease of the liear't or kidneys, but not the cardiac or renal lesions which are most frequently associated with dropsy. "They probably have a so-called "beerdrinker's heart" (whether due to drinking beer or some other relatively dilute alcoholic drink), and the walls of their minute blood vessels have probably become function. ally altered in some way by the vast quantities that they have been accustomed to drink. It may reasonably be supposed that in Horace's days such a dropsy occasionally occurred in men who liabitually drank (as many doubtless did) large quantities of diluted wine.

The explanation I have given appears to me the most probable, but I mention it merely as a suggestion, and I hope that it will not appear too fanciful to others. The alternative possibility is that Horace knew of the ordinary nephritic dropsy, which disappears when the inflammation of the kidneys passes off, but that, owing to some fanciful medical theories of the time, he erroneously supposed that the dropsy must usually be accompanied by great thirst.I am, etc.,

London, W., June 24th. F. Parkes Weber, M.D., F.R.C.P.

\section{DEATH AFTER NITROUS OXIDE-OXYGEN AND} LOCAL ANAESTHESIA.

SIR,-Dr. Dudley Buxton's suggestion of the dominating influence of the heart muscle in the case I reported in the Jounnal for July 22nd, p. 109, is rery feasible. Cases of acute dilatation of the heart under the influence of nitrous cxideoxygen were recorded years ago in the Transactions of the Society of Anaesthetists. Percussion of the cardiac dullness before operation in my case revealed no dilatation of the right side of the heart, but I suspect that some degree of myocarditis, or rather muscular degeneration, existed, and that anaemia caused by profuse haemorrhage made dilatation of the heart potential, leading to the train of events so well described by Dr. Buxton. The pupils were not at any time minutely contracted as in morphine poisoning, and the type of respiration was not that usually seen in this condition.

In reply to Dr. Buxton's questions, I would say that the cardiac area was not percussed after the iuitial difficulties had revealed themselves; and, unfortunately, post-mortem examination was not allowed to give information which would have been very valuable.

No attempt was made to massage the heart from the abdominal route when the fatal collapse occured, and I greatly doubt, if the method had been tried, that it would have had any success.

When circulatory failure became acute, the head and shoulders of the patient were lowered, but the acute Trendelenburg posture was not adopted.

With regard to the possibility of traumatic shock, the serious symptoms developed before the abdomen was opened. From my own experience I am inclined to believe that it is impossible to block inside the abdomen the traumatic effects of operation. Such a light anaes. thesia as that indicated by nitrous oxide-oxygen doss not mask the effects of trauma, as does the deeper anaesthesia of ether or chloroform; hence the result of local anaesthesia inside the abdomen can be better estimated. Personally I have little faith in the efficacy of injection of local anaes. thetics intra-abdominally, though for operation on the abdominal wall nerve blocking can be absolute.

Possibly transfusion of blood in moderate amount instead of infusion of saline solution would have been remedial if 
Dr. Buxton's theory that the heart was overwhelmed by intravenous infusion be correct.

I cannot help thinking that in certain types of case such as this the psychic factor plays an important part, and prepares the nervous mechanism of a heart already labouring under muscular disability to, as it were, collapse under strain. Mechanical and toxic causes alone will not always explain deaths during or after anaesthesia. Un. fortunately these different factors cannot be estimated but only guessed at beforehand.-I am, etc.,

Birmingham, Aug. lst.

W. J. McCardie.

\section{"THE FASTING TREATMENT OF DIABETES:"}

SIR, - I should like to express my thanks to Dr. Cam. midge for confirming my statements which he heard at the Royal Society of Medicine on May 16th, and for doing me the honour of paraphrasing some of $\mathrm{my}$ remarks.

It is unfortunate that Dr. Joln Hume's and Dr. Cammidge's letters appear under the same heading, because, in spite of Dr. Humo's treatment presenting certain similarities to that suggested by Allen (of the Rockefeller Institute), nevertheless the basis and details are very different.

It was the recognition that Guelpa's treatment was frequently referred to as the "fasting treatment" that led me to discuss Allen's treatment under the heading of "Treatment of Diabetes by Alimentary Rest." The advisability of distinguishing from all others the single treatment, which aims at, and succeeds in, the complete and permanent absence of sugar from the urine, will be accepted by all. I have no data to decide whether Guelpa or Hume was the earlier to treat diabetes by laxatives and short fasts. No doubt in both it was original if not novel.

The essential part of Allen's treatment is alimentary rest until the last trace of sugar has disappeared from the urine. The object of this does not seem to be recognized by all. Simultaneously with this disappearance there is an alteration of metabolism, which allows a much freer oxidation of carbohydrates. Until this has been accomplished food should be withheld. No case which has not had alimentary rest until the urine has become free from sugar should be considered to have undergone the Allen treatment.

Dr. Cammidge has drawn up a useful table; perhaps he will add to its value by publishing the number of analyses upon which it is based, and whether the vegetables have been gathered at various scas ins.

'To illustrate the importance of this I draw attention to his statement that $5 \mathrm{oz}$. of boiled turnips contain $1 \mathrm{gram}$ of carbohydrate. Atwater and Bryant, working in America, found that the percentage of carbolyydrates in turnips varied from 2.8 to 23.8 ; therefore, unless they are boiled in an extremely large quantity of water, it is unwise to assume that they will contain a constant amount of carbo. hydrate. Again, blackberries, according to the same observers, vary from 7.5 per cent. to 16.7 per cent.; Dr. Cammidge assumes that they contain about 10 per cent.

My experience (which, thanks to the authorities of the London Hospital, is now based on many dozens of cases) has taught me that those vegetables aud fruits which vary greatly in composition should be avoided.-I am, etc.

London, W., July 31st.

O. Leyton.

\section{THE SOLDIER'S HEART.}

Sir,-Sir James Barr has given me his answer at least so far as concerns his method of excluding from a share in the causation of "soldier's heart" that part of bacterial action which might be duo to dental sepsis. He allows that there may be areas of inflammation in the mouth, but asserts that these are not necessarily injurious. He allows the presence of foul breath, but apparently forgets that its owner is swallowing decomposing food.

That there can be no inflammation without some degree of general injury is a pathological axiom. That the swallowing of decomposing food is injurious is equally one of the first principles of hygiene. When it is realized that in a case of dental sepsis, in addition to the visible areas of inflammation there are generally concealed areas of in: flammation and sippuration, and that these latter areas often exist with little or no external sign, I think it will

be seen that Sir James Barr's exclusion of dental sepsis is indeed ill:founded.

My reason for entering this discussion was to disallow Sir James Barr's neglect of dental sepsis as a possibly important factor in any disease which may be of microbic causation.-I am, etc.,

London, W., Aug. 1st.

J. G. TURNER,

\section{TREATMENT OF "SHELL SHOCK."}

Sir,-I was deeply interested in Captain Milligan's article on this subject in your issue of July 15th, recom mending suggestion under what I have ventured to call "chloroform hypnosis." In a paper which I published in the Clinical Journal for March 1st last, entitled "Chloroform Hypnosis and Manual Aid during Protracted and Painful Labour," I pointed out the great value of moderate chloroform anaesthesia, whereby the patient who is in acute mental and badily suffering is quickly placed in a condition of passivity and suggestibility, wherein she can he encouraged to bear down and so assist natural expul. sion. For some time I have made constant use of this method, and, along with skilled manual aid, I find that the necessity for the use of forceps now is much less frequent The object of this communication is to draw attention to the value of chloroform hypnosis, not in obstetrical work only, but in a much larger field, whenever, in fact, we wish to abolish higher consciousness, with its many disturbing elements in highly strung neurotic patients, and to induce a condition of answerability to suggestion. I am therefore a strong advocate of Captain Milligan's method in all cases of traumatic lyysteria, as well as mere " shell shock," and, indeed, in all functional nerve disorders where sug. gestion treatment is indicated. Ordinary hypnotism no doubt will succeed in a certain number of these cases, but not many doctors have mastered its methods, and its many failures and the time and trouble required make it impracticable in these busy days, whereas chloroform hypnosis can generally be induced in five or ten minutes. Perhaps Captain Milligan could be induced to give further practical details of the employment of his method-I am, etc., Bowden, Cheshire,
July 15th.

\section{THE ARSENIC CONTENT OF SALVARSAN AND NEO-SALVARSAN.}

Sir,-It appears from recent medical literature that there is some misapprehension as to the percentage of arsenic contained in salvarsan ("kharsivan") and neosalvarsan ("neo-kharsivan"). Thus Staff Surgeon Sheldon F. Dudley, M.B., R.N., in a paper on galyl and neo. salvarsan, ${ }^{1}$ states that the latter contains 31.2 per cent. of metallic arsenic. This statement is accepted in the leading article appearing on page 118 of your issue of July 22nd, where the additional information is given that sal. varsan ("kharsivan") contains about 34 per cent. of arsenic. As a matter of fact, however, salvarsan (" kharsivan") contains about 31.6 per cent. of arsenic, whilst neo-salvarsan ("neo-kharsivan") contains about 21 per cent. of arsenic. The following historical notes will explain the cause of the confusion in each case.

Salvarsan. - The earlier circulars of the Farbwerke vorm Meister, Lucius und Brining, the manufacturers of salvarsan, stated that salvarsan "contains about 34 per cent. arsenic." In 1911, however, G. O. Gaebel ${ }^{2}$ found 31.2 and 31.8 per cent. $\mathrm{As}$ in salvarsan, and pointed out that these results agreed well with the figure 31.6 per cent. required for the formula $\mathrm{C}_{12} \mathrm{H}_{12} \mathrm{~N}_{2} \mathrm{O}_{2} \mathrm{As}_{2}, 2 \mathrm{HCl}, 2 \mathrm{H}_{2} \mathrm{O}$. 'This work was brought to the notice of Ehrlich, and in consequence the later circulars of the above mentioned firm no longer assert that salvarsan contains about 34 per. cent. of arsenic, but bear the statement "The As content of the preparation corresponds to the formula $\mathrm{C}_{12} \mathrm{H}_{1,2} \mathrm{~N}_{2}()_{2}$ $\mathrm{As}_{2} 2 \mathrm{HCl}+2 \mathrm{H}_{2} \mathrm{O}$." This statement applies equally to " kharsivan." Salvarsan and " kharsivan," thereforo, contain abont 31.6 per' cent. of arsenic.

Neo-salvarsan is stated by the Farbwerke rorm Meister Lucius und Brüning, to contain as the active constituon

\footnotetext{
1 Journ. Iroy. Naval Med. Service, 1915, 2, 283.
2 Apoth. Zeit., 1911, 26, 215.
} 